\title{
A ALOPOIESE DO DIREITO NA MODERNIDADE PERIFÉRICA BRASILEIRA COMO VEÍCULO DE LIBERTAÇÃO A PARTIR DO DIRIGISMO CONSTITUCIONAL
}

\author{
ALOPOIESIS OF THE LAW IN BRAZILIAN PERIPHERAL MODERNITY AS A VEHICLE OF \\ LIBERATION FROM CONSTITUTIONAL DIRIGISM
}

\section{LA ALOPOIESE DEL DERECHO EN LA MODERNIDAD PERIFÉRICA BRASILEÑA COMO VEHICCULO DE LIBERTACIÓN A PARTIR DEL DIRIGISMO CONSTITUCIONAL}

\section{Mário Lúcio Garcez Calil}

\section{Roberto da Freiria Estevão}

Licença CC BY:

Artigo distribuído sob os termos Creative

Commons, permite uso e distribuição

irrestrita em qualquer meio desde que o autor credite a fonte original.

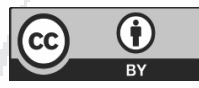

\begin{abstract}
Resumo: A teoria dos sistemas, que observa a sociedade como um conjunto de sistemas que se autoproduz e se influencia mutuamente, tem diversos adeptos no Brasil. Ocorre que a referida teoria não se adapta com facilidade a países de "modernidade tardia", de modo que, nesse contexto, ocorre a chamada "alopoiese", ou seja, a falta de normatividade do direito, por influência direta do ambiente no qual determinado sistema jurídico se encontra inserido. O objetivo do presente trabalho é estudar o chamado "dirigismo constitucional" como mecanismo de prevenção da alopoiese, especialmente a partir da Tese da Constituição Dirigente Adequada a Países de Modernidade Tardia, bem como as possibilidades libertadoras da democracia participativa nesse contexto, o que se faz por intermédio de pesquisa bibliográfica, de caráter qualitativo. Utilizou-se, na escrita, o método dedutivo. Concluiu-se que o "dirigismo constitucional" no contexto da modernidade periférica, apesar de não se referir diretamente ao paradigma sistêmico, pode promover a real normatividade do sistema jurídico, em especial, da Constituição.
\end{abstract}

Palavras-chave: Teoria dos Sistemas. Alopoiese. Modernidade Periférica. Constituição Dirigente.

1 Pós-doutorado (Bolsista PDJ-CNPQ) e estágio pós-doutoral (Bolsista PNPD-CAPES) pela Fundação Eurípides Soares da Rocha de Marília. Doutor em Direito pela Faculdade de Direito de Bauru (CEUB-ITE). Mestre em Direito. Professor Adjunto IV da Universidade Estadual de Mato Grosso do Sul. Vice-líder do grupo de pesquisa "Bioética e Direitos Humanos", vinculado ao Programa de Mestrado do UNIVEM. <mario.calii@yahoo.com.br>.

2 É Mestre em Direito pelo UNIVEM, Doutor em Ciências Sociais pela UNESP-Marília. Vice-líder do grupo de pesquisa "DIFUSO - Direitos Fundamentais Sociais". Professor titular do Centro Universitário Eurípides de Marília - UNIVEM/Fundação, de Marília, Membro do Ministério Público do Estado de São Paulo (Procurador de Justiça). Aposentado.<roberto_freiria@terra.com.br>. 
Abstract: Systems theory, which observes society as a set of systems that self-produce and influence each other, has many supporters in Brazil. But this theory does not adapt easily to countries of "late modernity", such that, in this context, a so-called "alopoiesis" occurs, i.e. a lack of normativity of the law, by direct influence of the environment in which a particular legal system is integrated. The aim of this work is to study the so-called "constitutional dirigisme" as a mechanism for preventing alopoiesis, especially based on the Theory of Constitutional Dirigism Suitable for Countries of Late Modernity (Tese da Constituição Dirigente Adequada a Países de Modernidade Tardia), as well as the liberating possibilities of participatory democracy in this context. This is done through bibliographic research of a qualitative character. The deductive method was used in the writing of the report. It is concluded that "constitutional dirigisme" in the context of peripheral modernity, despite the fact that it does not refer directly to the systemic paradigm, can promote real normativity of the legal system, especially the Constitution.

Keywords: Systems Theory. Alopoiesis. Peripheral Modernity. Constitutional Dirigism.

Resumen: La teoría de los sistemas, que observa la sociedad como un conjunto de sistemas que se auto-produce e influye mutuamente, tiene diversos adeptos en Brasil. Ocurre que la referida teoría no se adapta con facilidad a los países de "modernidad tardía", de modo que, en este contexto, ocurre la llamada "alopoiese", o sea, la falta de normativa del derecho, por influencia directa del ambiente en la cual determinado sistema jurídico se encuentra inserido. El objetivo del presente trabajo es estudiar el llamado "dirigismo constitucional" como mecanismo de prevención de alopoiese, especialmente a partir de la Tesis de la Constitución Dirigente Adecuada a Países de Modernidad Tardía, bien como las posibilidades libertadoras de la democracia participativa en este contexto, lo que se hace por intermedio de investigación bibliográfica, de carácter cualitativa. Se utilizó, en la escrita, el método deductivo. Se concluyó que el "dirigismo constitucional" en el contexto de la modernidad periférica, a pesar de no referirse directamente al paradigma sistémico, puede promover la real normativa del sistema jurídico, en especial, de la Constitución.

Palabras clave: Teoría de los Sistemas. Alopoiese. Modernidad Periférica. Constitución Dirigente.

\section{INTRODUÇÃO}

Há anos se vem trabalhando a teoria sistêmica de Niklas Luhmann no Brasil. Trata-se de tese complexa, que busca observar a sociedade como um conjunto de sistemas que mutuamente se influenciam, mas se produzem internamente, por si mesmos. Ocorre que a teoria tem pressupostos relativamente claros para que ocorra essa "autopoiese" dos sistemas.

A autopoiese, de conformidade com a tese Luhmanniana, atuaria como um fator de redução das complexidades de determinada sociedade, promovendo, no caso do direito, um fechamento normativo, com abertura cognitiva do sistema jurídico, fortalecendo as expectativas sociais. 
Nos países como o Brasil, onde as "promessas da modernidade" ainda não foram cumpridas, ao menos no que concerne ao sistema jurídico, referida "autopoiese" não pode ocorrer, tendo em vista que essa operação tem como pressuposto a superação de paradigmas "pré-modernos". Aqui, ocorre o oposto: ao invés de "autopoiese" ocorre "alopoiese".

Em contraposição à ausência de normatividade do sistema jurídicoconstitucional, foi trabalhada por J. J. Gomes Canotilho a teoria da Constituição Dirigente, que vincularia o legislador aos objetivos constitucionais. Ocorre que o próprio Canotilho tratou de rever sua tese, passando a aceitar a "relativização" da Constituição dirigente.

Ocorre que, paradoxalmente ao descumprimento das promessas da modernidade no Brasil, as possibilidades emancipatórias da Constituição de 1988 ainda não foram esgotadas. Assim, a utilização eficaz dos meios de participação direta nas políticas voltadas aos direitos fundamentais parece ser uma forma de aplacar os efeitos da modernidade tardia.

Destarte, é o objetivo do presente trabalho estudar a teoria dos sistemas de Niklas Luhmann no contexto de países de modernidade periférica, sob o prisma do fenômeno denominado por Marcelo Neves de "alopoiese", ou seja, a ausência de "fechamento normativo" do sistema jurídico, que ocasiona a inacessibilidade do direito.

Além disso, busca-se trabalhar a utilização do chamado "dirigismo constitucional" como mecanismo de prevenção da "alopoiese" do direito como falta de normatividade constitucional ("constitucionalização simbólica"), a partir das teorizações de J.J. Gomes Canotilho e Lenio Luiz Streck.

Após, busca-se estudar a ética da libertação em Enrique Dussel, como mecanismo voltado a evitar a alopoiese a partir da participação popular na concretização da constituição dirigente. Elege-se como problema da presente investigação a possibilidade de se utilizar o dirigismo constitucional como forma de amenizar o processo de alopoiese no Brasil. 


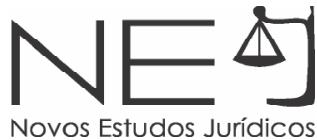

Para tanto, por intermédio de pesquisa bibliográfica, serão estudados os referenciais pertinentes, nacionais e estrangeiros. O presente trabalho é justificado, tendo em vista a influência da teorização Luhmanniana na doutrina nacional, bem como a necessidade de se estabelecer mecanismos de efetiva "positividade" da Constituição.

\section{NOTAS SOBRE O DIREITO COMO SISTEMA AUTOPOIÉTICO}

Para que se possa chegar a um conceito de "alopoiese" é necessário expor, ao menos de forma simplificada, do que se trata a chamada "teoria dos sistemas autopoiéticos". Trata-se de uma tese extremamente complexa e intrincada, de modo que apenas serão expostos aspectos basilares que se relacionam diretamente ao tema proposto. Luhmann desenvolveu, ao longo de sua vida acadêmica, uma teoria que procura, em síntese, expor a sociedade como um conjunto de sistemas de estrutura fechada, que se influenciam mutuamente. Referida doutrina há muito tem sido estudada no Brasil, na tentativa de transpôla à realidade nacional.

Em seu núcleo, a doutrina de Luhmann busca descrever como se legitima determinado tipo de sociedade sob determinadas condições, ${ }^{3}$ concluindo que cada sistema se "auto (re)produz", incentivado pelo ambiente no qual se encontra inserido e pelo contato com os demais sistemas. A palavra "autopoiese" surgiu de um conceito das ciências naturais, constante da teoria biológica de Maturana e Varela, derivando etimologicamente do grego autós ("por si próprio") e poíesis ("criação", "produção"), ${ }^{4}$ referindo-se à forma na qual os sistemas sociais se movimentam por si mesmos em um determinado ambiente. Apesar de "fechados", os sistemas sociais não restam isolados. O ambiente, mais do que condição estrutural ou perturbação do sistema, constitui seu fundamento. Aliás, aqui, a diferença entre sistema e meio, que possibilita a emergência do sistema, é a diferença mediante a qual o sistema já se encontra constituído.

3 ADEODATO, João Maurício. Ética e retórica: para uma teoria da dogmática jurídica. 4. ed. São Paulo: Saraiva, 2010, p. 106.

4 NEVES, Marcelo. A constitucionalização simbólica. São Paulo: Martins Fontes, 2007, p. 127.

5 LUHMANN, Niklas. Introdução à teoria dos sistemas. Petrópolis: Vozes, 2009, p. 101. 
O sistema se diz "fechado" porque opera do lado interno da forma, produzindo operações em si mesmo, não no outro lado da forma. Mas a operação no interior do sistema e não no meio pressupõe que o meio exista e esteja situado do lado de fora, de modo que a diferença entre sistema e meio é a diferença mediante a qual o sistema se constitui. ${ }^{6}$

A complexidade dos sistemas aumenta sua autonomia e sua dependência ao mesmo tempo, o que explicaria por que os sistemas político, econômico e jurídico são altamente dependentes e independentes em relação ao meio.? $\mathrm{A}$ teoria dos sistemas observa a redução de tais complexidades, por intermédio de um intrincado sistema de "expectativas".

É inegável que o direito, assim como a política e a economia, é um sistema social, que pode ser observado por intermédio da teoria Luhmanniana, podendo, também, se auto (re)produzir. Ocorre que o direito se diferencia dos demais sistemas, especialmente no que concerne às teorias que o consideram como um sistema aberto.

$\mathrm{Na}$ autopoiese do direito, a normatividade não é a finalidade em si do sistema; é, sim, condição de sua abertura. ${ }^{.}$A autorreferência pertence à realidade do direito como sistema social, não sendo tratada como um problema lógico, de modo que é condição imprescindível à unidade operacional e estrutural do sistema jurídico. ${ }^{9}$

É nesse quadro que o direito funciona como um "seletor de expectativas comportamentais", na busca pela redução de complexidades. A "autorreferencialidade" dos elementos que compõem o sistema jurídico é que permite ao Direito criar o direito ${ }^{10}$, que é, por isso, visto como "[...] um sistema normativamente fechado, mas cognitivamente aberto". ${ }^{1 .}$

Pela abertura cognitiva anteriormente referida, as influências do meio externo passam pelo processamento de seleção realizado pelo código direito/

LUHMANN, Niklas. Introdução à teoria dos sistemas, p. 122.

NEVES, Marcelo. A constitucionalização simbólica. São Paulo: Martins Fontes, 2007, p. 127.

NEVES, Marcelo. A constitucionalização simbólica, p. 127.

NEVES, Marcelo. A constitucionalização simbólica, p. 140.

TRINDADE, André. Para entender Luhmann. Porto Alegre: Livraria do Advogado, 2008, p. 52-82.

NEVES, Marcelo. Luhmann, Habermas e o Estado de Direito. Lua Nova. São Paulo, v. 37, p. 93-106, 1996, p 128. 


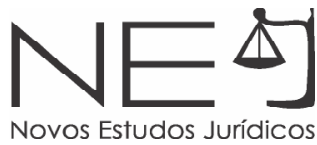

não direito, juridicizando elementos do meio que passam a integrar sua estrutura e servem de aparato para manter sua autorreferencialidade. ${ }^{12}$

Na relação entre sistema e meio caracterizada pela complexidade, o direito na sociedade moderna atua como forma de controle do código-diferença, "lícito/ ilícito" por um sistema funcional especializado. Para que tal operação possa ocorrer, pressupõe-se a superação da sociedade pré-moderna, diferenciada verticalmente. ${ }^{13}$

Em um cenário como o que se apresenta, de ausência de superação da "prémodernidade", é impossível que a ausência de "auto (re)produção" do sistema jurídico não tenha consequências dignas de nota. Dessa forma, é conveniente relacionar tal cenário com o atual estágio de evolução do Direito.

\section{A MODERNIDADE E O DIREITO}

A referência feita por Luhmann à superação do cenário pré-moderno como pressuposto para a autorreprodução do Direito importa na necessidade de se determinar o que seria "modernidade", ao menos em termos sociológicojurídicos, de modo a que se possa determinar se a sociedade brasileira teria ou não ultrapassado tal paradigma.

O fato de as sociedades demonstrarem, de forma idêntica, apenas o mesmo comprometimento com o industrialismo, põe em questão a substância do modernismo, sugerindo que, nesse aspecto, nunca existiu conexão entre os elementos da civilização europeia pós-renascentista. ${ }^{14}$

Ora, se o industrialismo é a única característica em comum do pósrenascentismo, o próprio conceito de modernidade "histórica" é colocado em voga, devendo, ao menos no contexto jurídico, ser observado por outro prisma. Ocorre que, também sob o prisma da democracia, o conceito sofre com a falta de relação entre os sistemas.

12 TRINDADE, André. Para entender Luhmann, p. 85.

13 NEVES, Marcelo. A constitucionalização simbólica, p. 127.

14 SANTOS, Boaventura de Souza. Pela mão de Alice: o social e o político na transição pós-moderna. São Paulo: Cortez, 1997, p. 148. 
Nesse contexto, a inexistência de relação entre elementos sociais faz com que o compromisso com a generalidade e autonomia da lei e com a distinção entre legislação, administração e jurisdição não tenha qualquer significado democrático natural, podendo ajudar na promoção de oligarquias ou mesmo de ditaduras. ${ }^{15}$ Dessa forma, exclusivamente sob o prisma normativo, é impossível formular um conceito de modernidade "jurídica" que se relacione com a superação do "pré-modernismo", que é um dos requisitos para a "autopoiese" do direito, de acordo com a teoria de Niklas Luhmann.

A modernidade é um projeto implementado progressivamente, voltado a responder a três violências ("triângulo dialético"): a falta de segurança e de liberdade; a desigualdade política; e a pobreza, ${ }^{16}$ elementos claramente relacionados aos "dogmas" da Revolução Francesa.

É claríssimo, no entanto que, em países como o Brasil, cujas relações sociais ainda são regidas pela estratificação, tais respostas ainda não foram dadas, de modo que o projeto nacional de modernidade não encontrou "progresso" suficiente, inclusive em termos estritamente normativo-constitucionais. As sociedades "proletárias" dependem de uma burocracia centralizada contraposta às oligarquias locais e aos grupos nacionais de interesse, bem como de um sistema legal universalista que restrinja o arbítrio dos superiores locais. Aqui, o tratamento igual de situações desiguais pelo judiciário confirma a desigualdade. ${ }^{1}$

No Brasil, as desigualdades latentes, ignoradas pela Administração e pela Legislatura e confirmadas pelo Judiciário, demonstram o completo fracasso do projeto nacional de modernidade. Exemplo disto é o pagamento do denominado "auxílio-moradia" aos Magistrados e Membros do Ministério Público da ativa, benesse prevista nas respectivas Leis Orgânicas da Magistratura e do Ministério Público nos âmbitos federal e estadual. O Conselho Nacional de Justiça (CNJ) aprovou, em 07 de outubro de 2014, a Resolução CNJ n. 199, que regulamentou a concessão desse auxílio-moradia. ${ }^{18}$

15 SANTOS, Boaventura de Souza. Pela mão de Alice: o social e o político na transição pós-moderna, p. 201.

16 CANOTILHO, José Joaquim Gomes. O estado adjetivado e a teoria da Constituição. Revista da Procuradoria Geral do Estado do Rio Grande do Sul, n. 17, v. 25. 2002, p. 27.

17 SANTOS, Boaventura de Souza. Pela mão de Alice: o social e o político na transição pós-moderna, p. 202.

18 BRASIL. Conselho Nacional de Justiça. Resolução n. 199. 2014, n.p. 
Igual procedimento tomou o Conselho Nacional do Ministério Público (CNMP) por meio da Resolução $n^{\circ}$. 117'19. Atualmente, o valor do auxílio é de $\mathrm{R} \$ 4.500,00$ (quatro mil e quinhentos reais) em média. Em algumas situações, há o pagamento duplicado a um casal - de Promotores, ou de Magistrados, ou formado por Membro do Ministério Público com Magistrado(a) -, que reside sob o mesmo teto e trabalha na mesma comarca.

Manifesta, no que concerne a isto, a situação de injustiça e desigualdade em relação aos demais cidadãos, muitos deles sofrendo violações ao fundamental direito à moradia. É possível afirmar, pois que a modernidade, ao menos no sentido jurídico, não chegou ao país.

\section{ALOPOIESE DO DIREITO E MODERNIDADE PERIFÉRICA}

Como se verificou, a "modernidade", ao menos em termos sistêmicos, necessita da separação de paradigmas "pré-modernos", especialmente no que concerne às desigualdades existentes em um determinado contexto social. Ocorre que a observação do contexto global determina que o fenômeno não ocorreu de maneira idêntica no mundo todo.

Aliás, o advento da sociedade moderna está vinculado a uma profunda desigualdade econômica no desenvolvimento inter-regional, que traz consequências significativas no que tange à reprodução de todos os sistemas sociais, especialmente o político e o jurídico, estatalmente organizados. ${ }^{20}$

Nesses termos, a modernidade periférica é caracterizada por um problema estrutural: "[...] desde o seu surgimento vincula-se à falta de suficiente autonomia operacional dos sistemas jurídico e político, bloqueados externamente por injunções diretas de critérios dos demais sistemas sociais, principalmente do econômico." 21

19 BRASIL. Conselho Nacional do Ministério Público. Resolução n. 117. 2014, n.p.

20 NEVES, Marcelo. A constitucionalização simbólica, p. 171.

21 NEVES, Marcelo. A constitucionalização simbólica. São Paulo: Martins Fontes, 2007, p. 173. 
A modernidade periférica é uma "modernidade negativa", tanto sob o ponto de vista sistêmico quanto de acordo com uma pretensão ético-procedimental. Dessa forma, o fracasso do projeto atinge tanto o sistema jurídico quanto o sistema político. Segundo o modelo de Luhmann, na modernidade periférica, a hipercomplexificação social e a superação do "moralismo" fundamentador da diferenciação hierárquica não cederam lugar à construção de sistemas sociais que se construam autonomamente no seu topos específico..$^{22}$

Em termos sistêmicos, a modernidade acaba por não se construir positivamente (como superação da tradição por meio do surgimento de sistemas autônomos e ação), mas apenas negativamente (como hipercomplexificação desagregadora do moralismo hierárquico tradicional). ${ }^{23}$

É evidente que a teoria Luhmanniana desenvolveu-se em um país de "modernidade central" e descreve, de maneira reconhecidamente eficaz, diversas situações presentes naquela sociedade, de modo que se faz necessário questionar a possibilidade de transposição da referida teoria para o cenário nacional.

O modelo Luhmanniano da autopoiese é intransponível à realidade jurídica da modernidade periférica, especialmente no caso do Brasil, tendo em vista a sobreposição do código econômico e do código político às questões jurídicas. Nesse contexto, o ambiente influencia diretamente a normatividade, tornando o sistema dependente do meio no que concerne à sua "produção". Nesse cenário, no qual o direito não se (re)produz por si mesmo, é cabível falar em "alopoiese", não em "autopoiese". ${ }^{24}$

$\mathrm{Na}$ alopoiese, o direito é incapaz de produzir generalização congruente de expectativas normativas a partir de diplomas legais, obscurecendo a própria distinção entre lícito e ilícito, tanto por falta de institucionalização quanto de identificação do sentido das normas, o que causa "[...] insegurança destrutiva nas relações de conflitos de interesses". ${ }^{25}$

22 NEVES, Marcelo. Luhmann, Habermas e o Estado de Direito. Lua Nova, p. 98.

23 NEVES, Marcelo. Luhmann, Habermas e o Estado de Direito. Lua Nova, p. 98-99.

24 NEVES, Marcelo. Luhmann, Habermas e o Estado de Direito. Lua Nova, p. 99-100. 


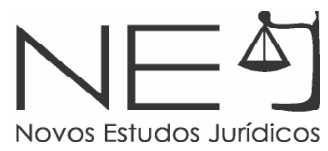

Nesse contexto, há falta de autonomia operacional do direito positivo estatal, de modo que códigos de comunicação, especialmente o econômico (ter/ não ter) e o político (poder/não poder), sobrepujam o código "lícito/ilícito", "[...] em detrimento da eficiência e mesmo racionalidade do direito. ${ }^{26}$

$\mathrm{Na}$ modernidade periférica, a falta de autonomia do direito e a sobreposição de poder e dinheiro ao direito são evidentes, o que se coloca diante do problema da relação entre instrumentalidade sistêmica e indisponibilidade do direito. Trata-se de falta de acesso ao direito e, portanto, de "subintegração" ao sistema jurídico. ${ }^{27}$

Os fundamentos da diferença entre países centrais e países periféricos são econômicos. A modernização progride no sentido de diversificar as necessidades. As regiões se tornam dependentes do sistema econômico mundial. Postos em contato com as estruturas locais, os sistemas afetam os modos de seleção racional, reforçando as discrepâncias já presentes: "[...] o bias econômico, então, gera um modelo centro/periferia, não necessariamente estável, mas cujos centros de gravidade podem ser rastreados". 28

É evidente que um direito "desigual" se torna indisponível e, portanto, não "generalizável". Se não é possível "generalizar" o direito, é impossível que se "auto (re)produza". E se a igualdade é pressuposto de superação do "pré-modernismo", em termos Luhmannianos, é impossível que o direito da modernidade periférica seja autopoiético.

Ora, se do nada, nada surge, da "não normatividade" não pode surgir "normatividade", de modo que falta ao sistema jurídico na modernidade periférica o elemento inicial para a autopoiese. Dessa forma, a "alopoiese" é um fenômeno amplamente perceptível no quadro jurídico nacional. Se o sistema econômico é desigual e produz ("alopoieticamente") o direito, este somente pode ser desigual e, portanto, alheio às reais necessidades sociais, em uma espécie de "autismo jurídico", sem autonomia e sem responsabilidade.

$26 \quad$ NEVES, Marcelo. A constitucionalização simbólica, p. 146.

27 NEVES, Marcelo. A constitucionalização simbólica, p. 100-103.

28 GOMES, Fernando. Constitucionalização simbólica ou constitucionalidade-simulacro? Exclusão, periferização e soberania popular no direito constitucional Brasileiro, DPU, p. 98-99. 
A relação entre o sistema jurídico e o contexto social brasileiro tem sido marcada pelo "fetichismo legal socialmente irresponsável", que não significa a autonomia operacional do direito como condição de abertura à diversidade de expectativas e interesses, mas, sim, um "autismojurídico", insensível aos problemas sociais. Assim, não se constrói uma interpretação-aplicação que, sem negar a autonomia funcional do sistema, seja orientada pelas consequências sociais das decisões jurídicas, impedindo o desenvolvimento de um "responsive law". ${ }^{29}$

Aliás, mais do que distante das demandas sociais, o direito corrobora (ativamente) as desigualdades latentes no sistema. Pode-se afirmar, nesse diapasão, que o "autismo" jurídico é apenas aparente, na medida em que a práxis nele envolvida é ressonante às discriminações sociais, fortificando-as. ${ }^{30}$

Como se observa, a autopoiese do direito é característica de países de modernidade central, tendo em vista que a influência do ambiente, nesses países, obedece ao sistema de expectativas observado por Luhmann. Resta, porém, questionar se haveria possibilidade de se ter, por exemplo, no Brasil, um direito autopoiético.

Seria necessário, como visto, que o direito fosse um sistema "normativamente fechado, mas cognitivamente aberto". Mas o que se observa é um fechamento cognitivo e uma abertura às normas impostas, em especial, pelo sistema econômico. No quadro de nulificação da normatividade, a própria Constituição sofre abalos em sua normatividade.

Nesse contexto de "periferia jurídico-estatal" que, como visto, torna propício o surgimento do autoritarismo e fortifica a desigualdade, é cabível buscar uma solução para o "fechamento" do sistema, vedando-o de influências externas que o impeçam de se "auto (re)produzir". Uma alternativa pode ser o chamado "dirigismo constitucional". 


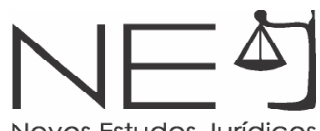

\section{A ALOPOIESE COMO "CONSTITUCIONALIZAÇÃO SIMBÓLICA" E A TESE DA CONSTITUIÇÃO DIRIGENTE APLICADA A PAÍSES DE MODERNIDADE TARDIA (TCDAPMT) E O DIREITO ALOPOIÉTICO}

No quadro proposto, a normatividade (especialmente a constitucional) perde espaço para o sistema econômico, deixando de se "auto (re)produzir". O fenômeno atinge a Constituição, tornando-a apenas "simulacro". "A constitucionalização simbólica como alopoiese do sistema jurídico é um problema fundamentalmente da modernidade periférica". ${ }^{31}$

Ao se tomar o caminho conceitual inverso, é possível asseverar, assim como Marcelo Neves, que "[...] a evolução social na direção da modernidade está estreitamente vinculada à construção do Estado de direito", ${ }^{32}$ que tem como evidente pressuposto a normatividade da Constituição, com destaque para sua função de "limite às decisões da maioria".

Explica-se: a Constituição, ao frear os mecanismos majoritários, abre caminho para a igualdade por meio do direito; não como pressuposto, mas como objetivo, o que é, como se expôs anteriormente, indispensável para que a autopoiese do direito possa efetivamente ocorrer.

A diferenciação exigida para a legitimação pelo procedimento pode nunca chegar. A sociedade pode manter-se estabilizada em um menor grau de complexidade, no qual grandes parcelas da população são excluídas dos procedimentos. ${ }^{3}$

O próprio Luhmann reconhece que existem regiões em que as premissas de diferenciação de sistemas sociais existem apenas em medida muito limitada, citando como exemplo o caso do Brasil, demonstrando que, no país, a evolução liberal do Estado Constitucional se realizou em termos largamente simbólicos. ${ }^{3}$

Isso porque não há funcionamento satisfatório da Constituição como "acoplamento estrutural" entre direito e política, como mecanismo de

$31 \quad$ NEVES, Marcelo. A constitucionalização simbólica, p. 147.

32 NEVES, Marcelo. Luhmann, Habermas e o Estado de Direito. Lua Nova, p. 93.

33 ADEODATO, João Maurício. Ética e retórica: para uma teoria da dogmática jurídica. 4. ed. São Paulo: Saraiva, 2010, p. 100.

34 CANOTILHO, José Joaquim Gomes. O estado adjetivado e a teoria da Constituição. Revista da Procuradoria Geral do Estado do Rio Grande do Sul, p. 33. 
Novos Estudos Jurídicos

interpenetração e interferência entre dois sistemas autopoiéticos. Ao contrário, há um bloqueio recíproco, "[...] principalmente no sentido da politização desdiferenciante do sistema jurídico". ${ }^{35}$

Mais do que referencial político ou jurídico, a constitucionalização atua como álibi: "[...] o 'Estado' apresenta-se como identificado com os valores constitucionais, que não se realizam no presente por 'culpa' do subdesenvolvimento da 'sociedade'"'. ${ }^{36}$ Ora, é justamente o oposto do que se observa do direito como sistema autopoiético.

O fenômeno encontra guarida até mesmo no sistema legislativo e em sua interpretação, que acaba por ocorrer de forma inversa no caminho da hierarquia das fontes do direito, de modo que a Constituição passa a ser interpretada de acordo com a Lei, sendo que deveria se perfazer justamente o caminho inverso.

$\mathrm{Na}$ constitucionalização simbólica, o direito é produzido pelo ambiente e, ao invés de normatizar, acaba por ser normatizado. É evidente, porém, que não se trata de um fenômeno novo, de modo que mecanismos teóricos de "constitucionalização efetiva" já foram elaborados, com destaque para um deles.

Uma teorização que influenciou de forma incisiva a doutrina nacional foi a elaborada por J.J. Gomes Canotilho acerca da Constituição Dirigente e a vinculação do legislador às suas disposições. Referida teoria foi largamente utilizada para combater a falta de normatividade das chamadas normas constitucionais "programáticas".

Esse "dirigismo constitucional" refletiu na interpretação da Constituição Federal de 1988, levando à conclusão de que é dotada, sim, de inegável vinculatividade. Mas, apesar de ser uma Carta repleta de disposições sobre direitos fundamentais, além de contemplar diversos outros instrumentos civilizatórios, sua normatividade é duvidosa. A própria normatividade da Constituição dirigente, no que se refere às políticas públicas e aos direitos sociais, é entendida como prejudicial aos interesses do país, causando crises econômicas, deficit público e "ingovernabilidade".

35 CANOTILHO, José Joaquim Gomes. O estado adjetivado e a teoria da Constituição. Revista da Procuradoria Geral do Estado do Rio Grande do Sul, p. 174-175.

36 CANOTILHO, José Joaquim Gomes. O estado adjetivado e a teoria da Constituição. Revista da Procuradoria Geral do Estado do Rio Grande do Sul, p. 176. 
Ou seja, a Constituição resta "forçada" a ser simbólica, sob pena de causar um colapso econômico. Ao ser limitada pelo sistema econômico, a Constituição deixa de ser "dirigente", passando a ser dirigida pelo ambiente no qual o sistema jurídico se encontra inserido. É a própria substância da alopoiese.

O "dirigismo constitucional", em perspectiva sistêmica, demanda que o direito comprove sua adequação como programa decisório, de modo que a positividade do direito possa ser concebida como "seletividade intensificada", ${ }^{37}$ voltado à redução da complexidade, não à sua confirmação.

Nesse quadro, a positivação do direito na sociedade moderna implica o controle do código-diferença "lícito/ilícito" pelo próprio sistema jurídico, que adquire seu fechamento operativo. ${ }^{38}$ Se assim não o for, opera-se, como visto, a alopoiese do direito, que passa a normatizar de acordo com outros sistemas.

É necessário questionar, portanto, acerca das possibilidades do dirigismo constitucional como mecanismo de "fechamento" do sistemajurídico. É necessário partir do pressuposto de que, no Brasil, a dimensão política da "constituição dirigente" tem uma força sugestiva relevante, quando associada à ideia de estabilidade, que Ihe deveria ser imanente..$^{39}$ Além disso, a Constituição dirigente desempenhará função de compreensão incontornável relativamente às tarefas do Estado. ${ }^{40}$ Nesse aspecto, se aplicado como mecanismo de frenagem dos ideais da "maioria" em detrimento da "minoria", o dirigismo constitucional poderia atuar como redutor de desigualdades no plano jurídico.

Apesar disso, Canotilho afirma que a relação entre a constituição dirigente e a teoria dos sistemas autorreferenciais é conflituosa, pois, se a Constituição dirigente se apoia no Estado e se a direção política estatal constitucionalmente conformada pretende irradiar para os demais sistemas, não teria aceitação ou cabimento na teoria sistêmica. ${ }^{4}$

$37 \quad$ TRINDADE, André. Para entender Luhmann, p. 61.

38 NEVES, Marcelo. A constitucionalização simbólica, p. 127.

39 CANOTILHO, José Joaquim Gomes. O estado adjetivado e a teoria da Constituição. Revista da Procuradoria Geral do Estado do Rio Grande do Sul, p. 27.

40 CANOTILHO, José Joaquim Gomes. O estado adjetivado e a teoria da Constituição. Revista da Procuradoria Geral do Estado do Rio Grande do Sul, p. 33-34.

41 CANOTILHO, José Joaquim Gomes. O estado adjetivado e a teoria da Constituição. Revista da Procuradoria Geral do Estado do Rio Grande do Sul, p. 34-35. 
Nesse diapasão, cumpre destacar que o próprio Canotilho declarou que a Constituição Dirigente estaria "morta" ao menos no que tange ao "engessamento" das possibilidades interpretativas constitucionais, especialmente no contexto de um "transconstitucionalismo" cuja formação era iminente para a Europa.

Não admite, porém, que tenha se baseado na perspectiva Luhmanniana para declarar a "morte" da Constituição dirigente. O constitucionalista assevera que se distancia da teoria dos sistemas autopoiéticos, declarando ainda prosseguir com um ideário "humanista".

Afirma, porém, que continua a defender as teorias acionalistas da política e da possibilidade de direção do Estado. Ocorre que o "pessimismo dirigente" perdeu seu lugar para as "instâncias atuantes", porém não desapareceu. A perspectiva autorreferencial deixa por resolver dois problemas: a tomada de decisões coletivamente vinculantes; e a legitimação para a tomada de decisões coletivas. Inicia uma autoevolução "sem sujeito", que demanda a transformação do Estado. ${ }^{42}$

Talvez a relativização da constituição dirigente, nos termos propostos por Canotilho, não represente, porsi, a autopoiese do direito em termos Luhmannianos. Mas, nos termos anteriormente propostos, tratando-se do direito de um país de modernidade periférica, somente confirma a alopoiese, por permitir a intromissão de outros sistemas no sistema jurídico.

Observe-se que a declaração de que a constituição dirigente estaria "morta" não foi bem recebida pela doutrina nacional, razão pela qual Canotilho se justificou, afirmando que a "morte" da Constituição não teria feito desaparecer toda a influência da teoria; apenas teria de se adaptar ao novo quadro jurídico e social do Século XXI.

Referida teorização tem impactado a doutrina de forma notável, tendo em vista que propõe que, em países a exemplo do Brasil (de modernidade periférica), não só é possível como é necessário extrair da própria Constituição a obrigatoriedade de cumprimento das promessas da modernidade.

42 CANOTILHO, José Joaquim Gomes. O estado adjetivado e a teoria da Constituição. Revista da Procuradoria Geral do Estado do Rio Grande do Sul, p. 35. 
A tese está em sentido oposto à relativização da Constituição dirigente proposta por Canotilho, que propõe, ao invés da normativização (termo sistêmico), uma regulação estatal, que permitiria uma evolução em termos jurídico-constitucionais, bem como a "transnacionalidade" da Constituição.

No Brasil, tal quadro se demonstraria impossível, tendo em vista que aqui ainda não foram cumpridas as promessas da modernidade, de forma que o país não se encontra em um estágio evolucional seguro o suficiente para admitir a desregulamentação, tendo em vista que nem mesmo foi, em sua história, um autêntico Welfare State.

De acordo com Lenio Streck, contudo, tal relativização não poderia se dar no contexto nacional, pois a Constituição brasileira não contém uma função normativo-revolucionária, ao contrário do que ocorreu em Portugal, de forma que os novos contornos da Constituição dirigente propostos por Canotilho deveriam ser contextualizados. ${ }^{43}$

Para adaptaros pressupostos da Constituição dirigente ao Brasil, Streck propõe uma adaptação, aliás, uma "adequação" da tese ao quadro de descumprimento das "promessas da modernidade" ("triângulo dialético"), que nomeia Teoria da Constituição Dirigente Adequada aos Países de Modernidade Tardia.

O preenchimento do deficit resultante do descumprimento das promessas da modernidade pode ser considerado um "conteúdo compromissário mínimo", que deve constar do texto constitucional, assim como os mecanismos de acesso à jurisdição constitucional e à participação democrática. ${ }^{4}$

Referida teorização tem impactado a doutrina de forma notável, tendo em vista que propõe que, em países a exemplo do Brasil (de modernidade periférica), não só é possível como é necessário extrair da própria Constituição a obrigatoriedade de cumprimento das promessas da modernidade.

Para o autor, enquanto o neoliberalismo aponta para a desregulamentação (estatal), a Constituição brasileira (ainda) aponta para a construção de um Estado

43 STRECK, Lenio Luiz. Jurisdição Constitucional e hermenêutica: perspectivas e possibilidades de concretização dos direitos fundamentais sociais no Brasil. Novos Estudos Jurídicos, v. 8, n. 2, p. 257-301, 2003, p. 275.

44 STRECK, Lenio Luiz. Jurisdição Constitucional e hermenêutica: perspectivas e possibilidades de concretização dos direitos fundamentais sociais no Brasil. Novos Estudos Jurídicos, p. 276. 
Social de índole intervencionista, pautado em políticas públicas distributivistas, o que se extrairia claramente do art. $3^{\circ}$ da Carta.

Assim, a tese da Constituição Dirigente Adequada a Países de Modernidade Tardia seria, ao menos em termos sistêmicos, capaz de promover o "fechamento normativo" do sistema jurídico a partir da Constituição, prevenindo e combatendo o fenômeno da alopoiese do Direito.

\section{A LIBERTAÇÃO DA ALOPOIESE A PARTIR DA PARTICIPAÇÃO POPULAR NA CONCRETIZAÇÃO DA CONSTITUIÇÃO DIRIGENTE}

De fato, nota-se, há muito, sério distanciamento entre o direito e a realidade social, como se a relação entre ambos fosse de velhos inimigos. Ora, esse "autismo jurídico" leva o direito a perder toda a sua essência e a razão de existência.

A libertação começa quando as vítimas se tornaram "novos sujeitos sócio-históricos" (movimentos sociais), a partir da tomada de consciência, organização, formulação de diagnósticos de sua negatividade e elaboração de programas de transformação do sistema vigente. ${ }^{46} \mathrm{O}$ reconhecimento da vítima nasce a partir do próprio reconhecimento de sua condição: "[...] a consensualidade crítica das vítimas promove o desenvolvimento da vida humana". Para que seja possível respeitar a dignidade do "outro", reconhecendo-o, é necessário, inicialmente, "dar lugar ao outro" para que possa "[...] intervir na argumentação não só como igual, com direitos vigentes, mas como livre, como outro, como sujeito de novos direitos" ${ }^{47}$

Essa "cultura do reconhecimento" deve surgir da dialética "opressoroprimido". Sem essa relação negativa, corre-se o risco de se retornar a uma "eticidade concreta", sem critérios de libertação. A Ética da Libertação ressalta que a consciência (ou o "saber-se afetado") resulta de um processo de conscientização por si só libertador: "[...] o 'encontro' com a vítima como o outro, como sujeito ético no 're-conhecimento' originário, é o a priori de toda ética, 'face-a-face'". ${ }^{48}$

45 STRECK, Lenio Luiz. Jurisdição Constitucional e hermenêutica: perspectivas e possibilidades de concretização dos direitos fundamentais sociais no Brasil. Novos Estudos Jurídicos, p. 278.

46 DUSSEL, Enrique. Ética da libertação: na idade da globalização e da exclusão. 2. ed. Petrópolis: Vozes, 2002, p. 546.

47 DUSSEL, Enrique. Ética da libertação: na idade da globalização e da exclusão, p. 415.

48 DUSSEL, Enrique. Ética da libertação: na idade da globalização e da exclusão, p. 421-422. 


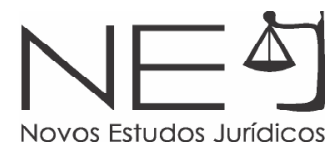

Nesse processo de "libertação", a vítima se descobre excluída. A partir daí, o próprio sistema que a excluiu deve passar a reconhecê-la como sujeito ético digno. Não só como igual, mas como passível de chegar a ser um "[...] pleno participante da nova comunidade real, possível, futura". Ao se descobrir "negada", a vítima começa a tomar consciência da existência de um "si mesmo positivo". Dessa primeira "consciência ingênua" começa a surgir uma "consciência crítica" que "desmistifica a realidade" e introduz o oprimido ao "imenso mundo da crítica". ${ }^{49}$

A análise teórica das causas da opressão é o meio pelo qual a vítima toma consciência da realidade que produz a sua opressão. Isso permite uma "[...] apreensão explicativa mínima do argumento de caráter reflexivo, teórico, crítico" e faz com que a subjetividade da vítima revele "[...] o sujeito que já não pode viver e grita de dor". ${ }^{50}$

É somente a partir desse (auto)reconhecimento que o "meio" pode passar a reconhecê-la como "outro": livre, igual e sujeito de direitos. Trata-se de uma etapa indispensável do processo de libertação. É logicamente impossível ser um sujeito de direito sem se reconhecer como um. Diante disso, a identidade se constrói a partir da percepção da opressão. No processo de "libertação", o uso da força contra os novos direitos (que se manifestam progressivamente aos olhos da vítima) já não será para ela fonte de "coação legítima", mas estritamente violência ou o "uso da força contra o direito do outro, sem validade nem consistência objetiva". O Direito tem de supor a situação de "negação discursiva" (material e formal) das vítimas. Os problemas da legalidade, da legitimidade, da coação de direito e tantos outros temas devem ser desenvolvidos em seu novo significado: a partir das vítimas. ${ }^{51}$

Trata-se de um modelo de reconhecimento que parte da vítima para o meio que a oprime. A "libertação" ocorre do âmbito "interno" para o "externo". Os grupos vulneráveis devem reconhecer que são vítimas de violência e opressão. Só então poderão assumir uma postura "crítica" acerca de sua posição.

49 DUSSEL, Enrique. Ética da libertação: na idade da globalização e da exclusão, p. 422-438.

50 DUSSEL, Enrique. Ética da libertação: na idade da globalização e da exclusão, p. 529.

51 DUSSEL, Enrique. Ética da libertação: na idade da globalização e da exclusão, p. 546-554. 
No contexto da participação democrática "libertadora", a Constituição deixaria de ser "simbólica", tornando-se, efetivamente, "normativa", pois vincularia o Estado ao cumprimento das promessas da modernidade, permitindo o fechamento normativo do sistema jurídico, mantendo, contudo, sua abertura cognitiva no que tange às demandas sociais.

A democracia administrativa parte da observância do direito à participação administrativa, consagrado na Constituição de 1988. A configuração do direito à participação nas decisões estatais comprova que, da perspectiva unidimensional Estado-súdito, passou-se à perspectiva bidimensional Estado-cidadão, pois a noção de cidadania é objeto de transformações, de modo que deve ser continuamente aprofundada em seu conteúdo e extensão. ${ }^{52}$

Indivíduos e organizações têm direito de pleitear a efetivação dos direitos fundamentais. As obrigações administrativas destinadas a conferir respostas a essas baseiam-se em competências e procedimentos fixados em lei, que decorrem das posturas a serem assumidas em decorrência das diretrizes e políticas públicas formuladas pelo Governo, em atendimento aos valores fundamentais previstos na Constituição de $1988 .{ }^{53}$

A principal tarefa da Administração mediadora é compor os conflitos sobre interesses estatais e privados, incluindo os cidadãos no processo de determinação e densificação do interesse público, que deixa de ser monopólio estatal. Os meios consensuais pela Administração são instrumentos da participação dos particulares no processo de tomada das decisões administrativas, "[...] possibilitando mais aceitação do que imposição, especialmente no âmbito das relações contratuais administrativas". ${ }^{54}$

É justamente neste ponto que reside o problema. Parece impossível afirmar que a sociedade brasileira tenha, de fato, superado sua condição pré-moderna, de evidente estratificação social. Dessa forma, a autorreferência do direito demonstra-se uma realidade distante.

52 OLIVEIRA, Gustavo Henrique Justino de. Direito administrativo democrático. São Paulo: Fórum, 2010, p. 159161.

53 OLIVEIRA, Gustavo Henrique Justino de. Direito administrativo democrático, p. 173.

54 OLIVEIRA, Gustavo Henrique Justino de. Direito administrativo democrático, p. 215-228. 


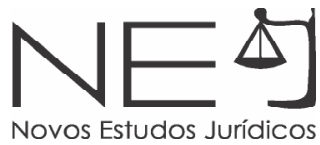

No contexto da autopoiese, a Constituição deixaria de ser "simbólica", tornando-se, efetivamente, "normativa", pois vincularia o Estado ao cumprimento das promessas da modernidade, permitindo o fechamento normativo do sistema jurídico, mantendo, contudo, sua abertura cognitiva no que tange às demandas sociais, promovendo, portanto, a libertação das vítimas da violência estatal, comissiva e omissiva.

\section{CONSIDERAÇÕES FINAIS}

A "teoria dos sistemas autopoiéticos" é uma tese extremamente complexa e intrincada, que procura, em síntese, expor a sociedade como um conjunto de sistemas de estrutura fechada, que se influenciam mutuamente, doutrina que há muito tem sido estudada no Brasil, na tentativa de transpô-la à realidade nacional.

Refere-se à forma na qual os sistemas sociais se movimentam por si mesmos, em um determinado ambiente, observando a redução de tais complexidades por intermédio de um intrincado sistema de "expectativas". O direito, assim como a política e a economia, é um sistema social, que pode ser observado na teoria Luhmanniana, podendo se auto (re)produzir.

O direito, todavia, se diferencia dos demais sistemas, especialmente no que concerne às teorias que o consideram como um sistema aberto. Em um cenário de ausência de superação da "pré-modernidade", é impossível que a ausência de "auto (re)produção" do sistema jurídico não tenha consequências.

O industrialismo é a única característica em comum do pós-renascentismo, de modo que o próprio conceito de modernidade "histórica" é colocado em voga, devendo ser observado por outro prisma que, por sua vez, deve incorporar a democracia, sob pena de sofrer com a falta de relação entre os sistemas.

Sob o prisma normativo, é impossível formular um conceito de modernidade "jurídica" relacionado à superação do "pré-modernismo", um dos requisitos para a "autopoiese" do direito. Em países como o Brasil, cujas relações sociais ainda são regidas pela estratificação, essas respostas ainda não foram dadas. 
Assim, o projeto nacional de modernidade não encontrou "progresso" suficiente, inclusive em termos estritamente normativo-constitucionais. Notese, como exemplo prático, o pagamento do auxílio-moradia a magistrados e membros do Ministério Público, a manifestar situação de injustiça e desigualdade em relação aos demais cidadãos.

A "modernidade", em termos sistêmicos, necessita da separação de paradigmas "pré-modernos", especialmente acerca das desigualdades existentes em um determinado contexto social. A observação do contexto global, todavia, determina que o fenômeno não ocorreu de maneira idêntica no mundo todo.

A teoria Luhmanniana desenvolveu-se em um país de "modernidade central" e descreve, de maneira eficaz, várias situações presentes em uma sociedade. Assim, faz-se necessário questionar a possibilidade de transposição da referida teoria para o cenário nacional.

Um direito "desigual" é indisponível e, portanto, não "generalizável" e, desse modo, de impossível "auto (re)produção". Se a igualdade é pressuposto de superação do "pré-modernismo", é impossível que o direito da modernidade periférica seja autopoiético.

Se do nada, nada surge, da "não normatividade" não pode surgir "normatividade". Assim, falta ao sistema jurídico na modernidade periférica o elemento inicial para a autopoiese, de maneira que a "alopoiese" é um fenômeno amplamente perceptível no quadro jurídico nacional.

Se o sistema econômico é desigual e produz ("alopoieticamente") o direto, este pode ser apenas desigual e, assim, alheio às reais necessidades sociais, em uma espécie de "autismo jurídico", sem autonomia e sem responsabilidade. Dessa maneira, a autopoiese do direito é característica de países de modernidade central, pois a influência do ambiente, nesses países, obedece ao sistema de expectativas Luhmanniano.

Seria necessário que o direito fosse um sistema "normativamente fechado, mas cognitivamente aberto". O que se observa, todavia, é um fechamento cognitivo e uma abertura às normas impostas, em especial, pelo sistema econômico. 
No quadro de nulificação da normatividade, a própria Constituição é abalada em sua normatividade. Na "periferia jurídico-estatal" que possibilita o surgimento do autoritarismo e fortifica a desigualdade, cabe buscar uma solução para o "fechamento" do sistema, selando-o de influências externas que o impeçam de se "auto (re)produzir".

Uma alternativa para esse contexto pode ser o chamado "dirigismo constitucional", que tem como pressuposto a normatividade da Constituição, com destaque para sua função de "limite às decisões da maioria", pois, ao frear os mecanismos majoritários, abre caminho para a igualdade por meio do direito, não como pressuposto, mas como objetivo, algo indispensável para que a autopoiese do direito possa efetivamente ocorrer.

É o oposto do que se observa do direito como sistema autopoiético, fenômeno que encontra guarida no sistema legislativo e em sua interpretação, que acaba por ocorrer de maneira inversa no caminho da hierarquia das fontes do direito. Assim, a Constituição passa a ser interpretada de acordo com a Lei; deveria, todavia, perfazer justamente o caminho inverso.

Na constitucionalização simbólica, o direito é produzido pelo ambiente e, ao invés de normatizar, acaba por ser normatizado. É evidente, porém, que não se trata de um fenômeno novo, de modo que mecanismos teóricos de "constitucionalização efetiva" já foram elaborados, com destaque para um deles.

Apesar de a Carta ser repleta de disposições sobre direitos fundamentais e contemplar vários outros instrumentos civilizatórios, sua normatividade é duvidosa. Isso porque a própria Constituição dirigente, acerca das políticas públicas e dos direitos sociais, é tida como prejudicial aos interesses do país, causando crises econômicas, deficit público e "ingovernabilidade".

Assim, a Constituição é "forçada" a ser simbólica, sob pena de causar um colapso econômico. Ao ser limitada pelo sistema econômico, a Constituição deixa de ser "dirigente", passando a ser "dirigida" pelo ambiente no qual o sistema jurídico se encontra inserido. Trata-se da própria substância da alopoiese que, ao invés de reduzir a complexidade, confirma-a. 
Aplicando-se como mecanismo de frenagem dos ideais da "maioria" em detrimento da "minoria", o dirigismo constitucional poderia reduzir as desigualdades no plano jurídico.

A relativização da constituição dirigente, nos termos propostos por Canotilho, não representa, por si, a autopoiese do direito em termos Luhmannianos. Tratando-se, porém, do direito de um país de modernidade periférica, somente confirma a alopoiese, ao permitir a intromissão de outros sistemas no sistema jurídico.

No Brasil, esse quadro é impossível, pois aqui ainda não foram cumpridas as promessas da modernidade. Assim, o país não está em um estágio evolutivo suficientemente seguro para admitir a desregulamentação, pois nem mesmo foi, em sua história, um autêntico Welfare State.

A tese da Constituição Dirigente Adequada a Países de Modernidade Tardia seria, ao menos em termos sistêmicos, capaz de promover o "fechamento normativo" do sistema jurídico a partir da Constituição, prevenindo e combatendo o fenômeno da alopoiese do Direito, pois, há muito, há um sério distanciamento entre o direito e a realidade social. Esse "autismo jurídico" leva o direito a perder toda a sua essência e a razão de existência. Somente a partir desse (auto)reconhecimento que o "meio" pode passar a reconhecê-la como "outro": livre, igual e sujeito de direitos. É uma etapa indispensável do processo de libertação, pois é logicamente impossível ser um sujeito de direito sem se reconhecer como um.

Já na teoria da libertação, a identidade se constrói a partir da percepção da opressão. É um modelo de reconhecimento que parte da vítima para o meio que a oprime, de maneira que a "libertação" ocorre do âmbito "interno" para o "externo". Os grupos vulneráveis devem reconhecer que são vítimas de violência e opressão para, então, assumirem uma postura "crítica" acerca de sua posição.

Na participação democrática "libertadora", a Constituição deixaria de ser "simbólica", tornando-se "normativa", ao vincular o Estado ao cumprimento das promessas da modernidade, permitindo o fechamento normativo do sistema jurídico, mantendo, todavia, sua abertura cognitiva no que tange às demandas sociais. 


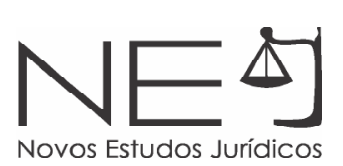

\section{REFERÊNCIAS}

ADEODATO, João Maurício. Ética e retórica: para uma teoria da dogmática jurídica. 4. ed. São Paulo: Saraiva, 2010.

BRASIL. Conselho Nacional de Justiça. Resolução n. 199. 2014. Disponível em: <www.cnj.jus. br>. Acesso em: 29 mar. 2018.

. Conselho Nacional do Ministério Público. Resolução n. 117. 2014. Disponível em: <www.cnmp.mp.br>. Acesso em: 29 mar. 2018.

CANOTILHO, José Joaquim Gomes. O estado adjetivado e a teoria da Constituição. Revista da Procuradoria Geral do Estado do Rio Grande do Sul, n. 17, v. 25, p. 25-40, 2002.

DUSSEL, Enrique. Ética da libertação: na idade da globalização e da exclusão. 2. ed. Petrópolis: Vozes, 2002.

GOMES, Fernando. Constitucionalização simbólica ou constitucionalidade-simulacro? Exclusão, periferização e soberania popular no direito constitucional Brasileiro. DPU, $n^{\circ} 22$, p. 83-103, jul.-ago., 2008.

LUHMANNN, Niklas. Introdução à teoria dos sistemas. Petrópolis: Vozes, 2009.

NEVES, Marcelo. A constitucionalização simbólica. São Paulo: Martins Fontes, 2007. . Luhmann, Habermas e o Estado de Direito. Lua Nova, São Paulo, v. 37, p. 93-106, 1996.

SANTOS, Boaventura de Souza. Pela mão de Alice: o social e o político na transição pósmoderna. São Paulo: Cortez, 1997.

STRECK, Lenio Luiz. Jurisdição Constitucional e hermenêutica: perspectivas e possibilidades de concretização dos direitos fundamentais sociais no Brasil. Novos Estudos Jurídicos, v. 8 , n. 2, p. 257-301, 2003.

TRINDADE, André. Para entender Luhmannn. Porto Alegre: Livraria do Advogado, 2008.

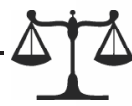

